\title{
POLÍTICA FISCAL E CICLOS ECONÔMICOS NO BRASIL
}

\author{
Manoel Carlos de Castro Pires*
}

\begin{abstract}
Resumo
Como se comporta o multiplicador fiscal? A literatura recente aponta que o multiplicador fiscal resulta de uma série de fatores dentre os quais se destaca seu comportamento em relação ao ciclo econômico, sendo mais elevado em períodos recessivos. Este artigo analisa esse comportamento por meio de modelos Markov-Switching. Os resultados indicam robustez do multiplicador de investimento público, sendo maior que um, e da carga tributária líquida, que é negativo. Além disso, os resultados encontrados mostram que os multiplicadores são mais relevantes em períodos de menor volatilidade.
\end{abstract}

Palavras-chave: Política fiscal; Ciclos econômicos; Investimento público.

\begin{abstract}
The recent literature argues that the economic cycle is a very important factor behind the way fiscal multiplier behaves, being larger during recessions. This paper analyses fiscal multiplier during distinct regimes by applying Markov-Switching models for Brazil. The results show that public investment multiplier is higher than one and net tax burden multiplier is negative. Furthermore, fiscal multipliers are robust and higher during periods of lower volatility.
\end{abstract}

Keywords: Fiscal policy; Economic cycles; Public investment.

JEL classification: E32, E62, H30.

DOI: http://dx.doi .org/10.1590/1413-8050/ea350

\footnotetext{
* IPEA. E-mail: manoel.pires@ipea.gov.br
} 


\section{Introdução}

A resposta de política econômica à crise financeira e a lenta recuperação da atividade econômica, instigou uma série de estudos que buscaram avaliar o impacto da política fiscal sobre o crescimento econômico, revigorando a literatura sobre multiplicadores fiscais. O ponto de partida desse novo ciclo de discussão se deu com o lançamento do American Recovery and Reinvestment Plan lançado em 2009 nos EUA. Esse programa justificou o plano de ação fiscal do governo americano a partir do estabelecimento de multiplicadores fiscais substanciais (Bernstein \& Romer 2009).

Em um primeiro momento, muitos questionamentos se seguiram tanto no que diz respeito aos multiplicadores divulgados (Cogan et al. 2010) quanto à própria eficácia dos pacotes de estímulos dessa natureza (Taylor 2011).

É importante ter claro que o multiplicador fiscal não é um parâmetro estrutural da economia. Ele descreve a resposta das variáveis endógenas da estrutura do modelo a mudanças nas variáveis fiscais. Assim, em um segundo momento, a literatura foi avançando para entender sobre quais condições o multiplicador pode ser elevado (Hall 2009). Com efeito, Woodford (2010) mostrou como o multiplicador fiscal é influenciado pelo tipo de política monetária que é adotada pelo Banco Central. Seus resultados mostram que o multiplicador é bem elevado nas condições em que se atinge o limite inferior para taxa de juros, o que, de certa forma, confirma os resultados alcançados por Bernstein \& Romer (2009).

Hall (2009), por sua vez, apresenta uma discussão bastante completa a respeito dos fatores que afetam o tamanho dos multiplicadores fiscais. Nesse sentido, um fator adicional que é importante para o tamanho do multiplicador é o formato da função consumo: quando o consumo dos agentes depende da renda disponível, a política fiscal tende a ser mais eficaz. ${ }^{1}$ Seguindo essa linha, Eggertsson \& Krugman (2010) mostram que a política fiscal pode ter impacto substancial na atividade econômica na medida em que consegue aliviar restrições de liquidez de indivíduos que após se endividarem, tenham que se desalavancar rapidamente. ${ }^{2}$

Esses resultados teóricos têm ressaltado cada vez mais a importância de avaliar o tamanho do multiplicador fiscal levando-se em consideração as condições econômicas presentes e também o arcabouço de política econômica adotado. Essa reflexão tem levado os economistas a concluir que os multiplicadores fiscais são dependentes do estado da economia. Ao considerar essa característica torna-se possível estabelecer de forma mais adequada políticas que visem estabilizar a demanda agregada.

Este artigo tem por objetivo apresentar evidências da relação do multiplicador fiscal com a evolução do ciclo econômico para o Brasil. Com efeito, a primeira contribuição é a exploração de uma base de dados ainda pouco utilizada que decompõe o multiplicador fiscal entre o consumo do governo, investimento público e a carga tributária líquida.

A segunda contribuição é que a análise se dará a partir de modelos MarkovSwitching, mais adequados para análise não linear do tamanho do multiplicador fiscal. Esses modelos têm como aplicação clássica a estimação de ciclos

\footnotetext{
${ }^{1}$ Outros fatores importantes para a discussão sobre o tamanho do multiplicador são: (i) a dinâmica do mercado de trabalho, (ii) a persistência do gasto público e; (iii) a composição da política fiscal.

${ }^{2}$ Uma linha semelhante havia sido adotada por Gali et al. (2007).
} 
econômicos e sua decomposição em regimes de recessão e expansão, de alta e baixa volatilidade, dentre outras. Em nosso conhecimento, essa metodologia ainda não foi utilizada para investigar o tamanho dos multiplicadores fiscais para o Brasil e como os mesmos se comportam nas fases distintas do ciclo econômico.

Para tanto, este artigo conta com mais cinco seções além desta introdução. A próxima seção faz uma breve descrição da literatura empírica recente. A terceira seção descreve a base de dados e a metodologia. A quarta seção caracteriza os ciclos de crescimento econômico na economia brasileira. A seção seguinte apresenta as evidências empíricas. Por último, seguem as principais conclusões do artigo.

\section{Literatura Empírica Recente}

Os estudos empíricos recentes sobre o multiplicador fiscal mostram uma grande dispersão de resultados. Esta elevada dispersão parece refletir a distinção de períodos analisados e uma série de preocupações metodológicas que se fizeram presentes e que foram sendo objeto de tratamento especial.

O ponto de partida desse debate se deu com os resultados empíricos obtidos por Blanchard \& Perroti (2002) que a partir de modelos SVAR (Structural Vector Autoregression) encontraram multiplicadores fiscais para os gastos que poderiam variar entre 0,90 e 1,29 e para a carga tributária variando entre $-0,75$ e $-0,50$. Seus resultados serviram para renovar o interesse de economistas no tema e, a partir de vários questionamentos, levaram cada vez mais a novos resultados.

No âmbito das evidências obtidas a partir de Blanchard \& Perroti (2002) os questionamentos se deram basicamente na identificação do SVAR, mais especificamente, com relação à hipótese de que os gastos do governo fossem verdadeiramente exógenos. A resposta que a literatura deu a essa potencial fragilidade foi restringir esse novo conjunto de evidências aos gastos militares norte-americanos. Esse tipo de gasto poderia ser considerado exógeno na medida em que a decisão de elevá-los teria pouca relação com o ciclo econômico.

Perroti (2008) aplica essa metodologia concluindo por multiplicadores dos gastos em torno de 0,7. Ainda que o problema da exogeneidade pudesse ter sido resolvido, há que se destacar que esse tipo de experimento tem pouca aplicabilidade, no sentido de que ele não poderia ser replicado para efeito de suavização de ciclo econômico, pois é difícil imaginar que os gastos militares possam ser utilizados para essa finalidade.

Com vistas a resolver o problema de identificação de outra forma, Mountford \& Uhlig (2009) criaram um método alternativo de identificação para o VAR que cria restrições ao comportamento das funções de impulso resposta. Essas restrições são conhecidas como "restrições de sinal" e impedem que as funções de impulso resposta assumam trajetórias distintas do esperado. ${ }^{3}$ Para esse tipo de identificação, o multiplicador fiscal dos gastos seria em torno de 0,65 e das receitas de $-0,5$.

\footnotetext{
${ }^{3}$ A motivação original para a aplicação dessa metodologia foi corrigir o que em modelos de transmissão de política monetária é conhecido como price puzzle que se refere à evidência de que os preços inicialmente sobem com um choque positivo de política monetária.
} 
Uma metodologia alternativa adotada pela literatura é a abordagem narrativa, que busca identificar nos registros históricos os momentos em que os choques fiscais podem de fato ser considerados exógenos. Essa literatura tem obtido resultados bastante expressivos, normalmente, concluindo em favor de multiplicadores bem maiores do que a unidade. São exemplos dessa literatura, Krenn \& Gordon (2010) que revisitam os choques fiscais na $2^{\mathrm{a}}$ Guerra Mundial e concluem por multiplicadores fiscais em torno de 1,8 e Almunia et al. (2009) que revisitam o período da grande depressão concluindo por multiplicadores entre 1,2 e 2,5 .

Ramey (2011) mostra que além da abordagem narrativa solucionar os problemas de endogeneidade, ela também é útil para revisitar o momento dos choques. ${ }^{4}$ Suas evidências mostram multiplicadores mais robustos quando é feita uma correção para identificar o momento mais apropriado do choque fiscal concluindo por multiplicadores entre 0,6 e 1 .

Além do debate em torno da melhor forma de identificação do choque fiscal, parte da literatura tratou das mudanças do multiplicador fiscal, ocorridas em função do estado da economia. Em períodos de baixo crescimento, o tradicional efeito crowding out torna-se pouco aplicável, pois a disponibilidade de recursos ociosos tende a impedir que esse efeito ocorra. Além disso, a proporção das famílias com restrição de endividamento tende a ser maior nessas circunstâncias. Essa lógica revisita a idéia keynesiana de que a política fiscal seria particularmente eficaz durante recessões (FMI 2010). ${ }^{5}$ Assim, é importante considerar nas especificações econométricas a possibilidade de existência desse tipo de não linearidade.

A evidência empírica a respeito da dependência de estado do multiplicador fiscal é muito recente e, portanto, escassa. Mittnik \& Semmler (2011) a partir de um modelo de VAR com regimes de threshold mostram que a atividade econômica na economia americana é bem caracterizada a partir de um regime de elevado crescimento e de um regime de baixo crescimento. Auerbach \& Gorodnichenko (2011), a partir da mesma família de modelos, apresentam evidências para a economia norte-americana de que o multiplicador fiscal para os gastos durante as recessões situa-se entre 1 e 1,5 e para as receitas próximos de zero. ${ }^{6}$

Esses resultados, ainda que de forma preliminar por conta da pequena quantidade de estudos que seguem essa abordagem, em conjunto com os modelos teóricos têm dado suporte à idéia de que os multiplicadores fiscais tendem a ser mais elevados durante recessões.

Para o caso específico do Brasil, as evidências empíricas são ainda mais escassas. Cavalcanti \& Silva (2010), por exemplo, estimam os multiplicadores fiscais para a economia brasileira para o período 1995 a 2008 seguindo a metodologia de Blanchard \& Perroti (2002) e utilizando dados de gastos e receitas públicas que incluem as três esferas de governo. O principal resultado do estudo é reconhecer que a política fiscal é relevante, mas que seu impacto tende a ser menor nos modelos que consideram a dinâmica da dívida pública. As-

\footnotetext{
${ }^{4}$ No caso japonês, Posen (1998) mostra que a dificuldade de identificar o tamanho do impulso fiscal e a sua duração têm levado à impressão de que a política fiscal seria inócua para recuperar economias em recessão.

${ }^{5}$ As evidências apresentadas pelo FMI para os países do G-7 confirmam a evidência de que os multiplicadores são maiores durante períodos recessivos.

${ }^{6}$ Em um estudo posterior Auerbach \& Gorodnichenko (2012) chegam à mesma conclusão ao estender a análise para os principais países da OCDE.
} 
sim, seus resultados indicam que a política fiscal é mais eficiente nas situações em que a dívida pública esteja sobre controle.

Em estudo relativamente similar, do ponto de vista metodológico, Peres \& Ellery (2009) também estimam um VAR utilizando os gastos do governo federal e as receitas federais. Os autores concluem que a política fiscal brasileira possui efeitos próximos aos postulados em modelos keynesianos, ou seja, de que os multiplicadores dos gastos são positivos em torno de 0,3 e da receita situam-se em torno de $-0,2$.

Pires (2011) estima um modelo VAR utilizando os dados de consumo do governo, os investimentos públicos e a carga tributária líquida das três esferas de governo para o período 1996 a 2011. Seus resultados indicaram que o multiplicador fiscal no Brasil tende a ser maior que um, sendo o multiplicador dos investimentos mais elevado que o do consumo do governo.

\section{Descrição da Análise Empírica}

A escassez de estudos de multiplicador fiscal para o Brasil reflete a dificuldade com os dados atualmente disponíveis. Como exemplo, Cavalcanti \& Silva (2010) estimam as despesas primárias pela diferença entre a carga tributária bruta e o resultado primário e, portanto, não conseguem separar as transferências de renda, o consumo do governo e os investimentos públicos, se limitando a uma medida muito agregada de política fiscal.

Peres \& Ellery (2009), por sua vez, se restringem a analisar o impacto da política fiscal do Governo Federal, pois este divulga dados mais detalhados em seu sistema contábil. ${ }^{7}$ Pires (2011) estima multiplicadores fiscais a partir de dados do consumo do governo, investimento público e carga tributária líquida das três esferas de governo a partir do esforço de pesquisa realizado pelo IPEA (Dos Santos 2008, Dos Santos et al. 2011).

\subsection{Descrição dos Dados}

A base de dados utilizada nesse estudo é uma atualização da utilizada em Pires (2011). Essas informações encontram-se, atualmente, disponíveis a partir de uma série de pesquisas realizadas pelo IPEA que divulgaram estimativas trimestrais dos investimentos públicos e da carga tributária líquida das administrações públicas. ${ }^{8}$ Essas informações foram deflacionadas, respectivamente, pelo INCC e pelo deflator do PIB e ambas dessazonalizadas pelo método X12-arima. A vantagem das evidências a serem reportadas é, portanto, o uso de informações novas e mais consistentes para análise dos multiplicadores fiscais. A análise cobre o período amostral entre o segundo trimestre de 1996 até o quarto trimestre de 2012.

No caso dos investimentos públicos e da carga tributária líquida, não existe em nosso conhecimento outra base de dados que consolide informações dos

\footnotetext{
${ }^{7}$ A omissão da dinâmica dos demais entes da federação tende a comprometer a robustez dos resultados tendo em vista que estes podem atuar na direção oposta à política fiscal do governo federal. Esse efeito parece ter afetado o American Recovery and Reinvestment Plan (Taylor 2011).

${ }^{8}$ Para análise das metodologias e fonte de informações que geraram esse conjunto de dados ver, Dos Santos (2008), Dos Santos et al. (2011).
} 
três entes da federação em base trimestral para o Brasil. Além dessas novas informações será utilizado o consumo do governo e o PIB, estimados pelo IBGE. ${ }^{9}$

A Figura A.1 (Apêndice) apresenta a evolução da taxa de crescimento do consumo do governo. É importante destacar que a série apresenta uma observação aberrante logo no seu início e que depois possui comportamento bastante regular com crescimento médio positivo e rápida reversão para a média, apresentando, portanto, baixa persistência. Durante o ano de 2009, o consumo do governo cresceu a taxa positivas, mas moderadas e decrescentes até o final de 2010. Conforme mostra a literatura, esse comportamento mais persistente pode ter sido importante para a recuperação anticíclica durante a crise financeira internacional. ${ }^{10}$

A Figura A.2 (Apêndice) apresenta a evolução da taxa de crescimento dos investimentos públicos. Diferentemente do consumo do governo, os investimentos públicos possuem elevada volatilidade. Uma característica marcante é a elevação da taxa de crescimento dos investimentos públicos a partir de 2006. Enquanto a taxa de crescimento entre 1996 e 2005 foi de $0,87 \%$ ao trimestre, a taxa de crescimento entre 2006 e 2012 foi de 2,37\% ao trimestre. Além disso, a volatilidade da série se reduziu substancialmente. É possível perceber que seu comportamento durante o período 2009-10 foi bastante expansionista tendo sido revertido no ano seguinte apresentando queda em vários trimestres ao longo dos anos de 2011 e 2012.

A Figura A.3 (Apêndice) descreve a evolução da carga tributária líquida que assim como o investimento público apresenta elevada volatilidade. Enquanto são conhecidos os efeitos de reformas tributárias anteriores que geraram substancial ganho de arrecadação, é importante notar sua dinâmica no período da crise internacional. Essa foi a primeira variável fiscal a refletir os efeitos da crise. No quarto trimestre de 2008, a carga tributária líquida caiu $11 \%$ após, seguidos trimestres de elevação substancial. A sua recuperação se deu apenas no terceiro trimestre de 2009 quando volta a apresentar crescimento positivo. Essa queda foi prolongada, não apenas por conta dos estabilizadores automáticos, mas também pelo aumento das transferências de renda e por uma série de desonerações feitas com o objetivo de administrar a demanda agregada. Em 2012 a carga tributária líquida apresentou comportamento análogo ao observado durante a crise financeira internacional.

\subsection{Descrição da Metodologia}

Um modelo Markov switching de regressão dinâmica (MS(s1,s2, s3, s4)-DIR(i, j)) pode ser descrito pelo seguinte processo:

$$
y_{t}=\mu\left(s_{1 t}\right)+\sum_{i=1}^{n} \alpha_{i}\left(s_{2 t}\right) y_{t-i}+\sum_{j=0}^{p} \beta_{j}\left(s_{3 t}\right) x_{t-j}+e\left(s_{4 t}\right), e_{t} \sim N\left[0, \sigma_{s 4}^{2}\right]
$$

\footnotetext{
${ }^{9}$ A literatura internacional tende a utilizar as despesas governamentais de forma mais direta. Optou-se por utilizar o consumo do governo, pois é uma medida que abrange os três níveis governamentais. Além disso, não existe um deflator apropriado para as despesas governamentais o que poderia influenciar nos resultados. No entanto, reconhece-se que é necessário avançar em uma medida mais apropriada de despesas governamentais para esse tipo de análise.

${ }^{10}$ Hall (2009) mostra que quanto maior a persistência do consumo do governo maior o multiplicador.
} 
onde $s_{1 t}$ é o número de estados determinado para cada componente do modelo, $i$ é o número de defasagens do componente dinâmico e $j$ é o número de defasagens do vetor de variáveis exógenas. O termo de erro possui média zero e variância que também depende da existência de regimes distintos.

A variável que determina o estado da natureza é regida por um processo estocástico conhecido como cadeia de Markov e definido por uma matriz de probabilidades de transição, cujos elementos são dados por:

$$
p_{k l}=\operatorname{Pr}\left(s_{t+1}=k \mid s_{t}=l\right), \sum_{k, l}^{m} p_{k l}=1 \text { e } p_{i j} \geq 0 \forall k, l=1 \ldots m
$$

Como exemplo, um modelo MS(2, 0, 0,2)-DIR $(1,0)$ pode ser descrito da seguinte forma:

$$
\begin{gathered}
y_{t, 1}=\mu\left(s_{1}\right)+\alpha y_{t-1}+e\left(s_{1}\right)_{t} \\
y_{t, 2}=\mu\left(s_{2}\right)+\alpha y_{t-1}+e\left(s_{2}\right)_{t} \\
P=\left[\begin{array}{ccc} 
& s_{t}=1 & s_{t}=2 \\
s_{t+1}=1 & p_{1 \mid 1} & p_{1 \mid 2} \\
s_{t+1}=2 & p_{2 \mid 1} & p_{2 \mid 2}
\end{array}\right]
\end{gathered}
$$

que descreve a variável dependente como seguindo dois regimes que diferem entre si pela média e pela sua volatilidade. Além disso, essa formulação estabelece um componente dinâmico comum aos dois regimes. Como se pode observar, a vantagem de modelos MS-DIR é a sua flexibilidade. Com efeito, a escolha da formulação mais adequada pode ser realizada a partir de métodos usuais de adequação de modelos dinâmicos como o critério de Akaike (AIC), testes de não linearidade (LR) e análise de normalidade de resíduos.

Em relação ao procedimento de estimação será utilizado o feasible non linear programming elaborado por Lawrence \& Tits (2001) por sua maior eficiência computacional. No entanto, cabe destacar que quando se trata de estimação de modelos não lineares é importante preocupar-se com alguns procedimentos utilizados. Com efeito, é comum que o algoritmo de maximização encontre máximos locais, mas não globais sendo influenciado pelo valor inicial que é utilizado pelo algoritmo. Assim sendo, é importante determinar se os resultados são robustos em relação a pontos iniciais distintos para que o algoritmo de maximização não produza resultados inconsistentes. ${ }^{11}$

Uma vez estimado o modelo, é de interesse analisar se a estimação não linear produz ganhos em relação à abordagem linear. Normalmente os testes de não linearidade não são identificados sob a hipótese nula de modo que o teste LR não possui a distribuição $\chi^{2}$ assintótica convencional (Teräsvirta 2006). Uma solução é reportar a aproximação para o limite superior da estatística LR conforme derivado por Davies (1987).

\footnotetext{
${ }^{11}$ Os resultados a serem apresentados passaram por análise de robustez em relação aos pontos iniciais utilizados e se mostraram adequados.
} 


\subsection{Questões práticas sobre o multiplicador fiscal}

Os estudos empíricos que estimam multiplicadores fiscais normalmente estimam elasticidades que posteriormente são transformadas em multiplicadores. Segundo Hall (2009), a conversão da elasticidade em um multiplicador fiscal é obtida a partir da divisão da elasticidade obtida pelo razão entre a variável fiscal sobre a variável dependente, no caso o PIB.

Essa conversão é possível a partir da própria definição de elasticidade $(\varepsilon)$ entre duas variáveis $(Y, X)$ :

$$
\varepsilon_{Y, X}=\frac{\left(\frac{\Delta Y}{Y}\right)}{\left(\frac{\Delta X}{X}\right)}=\left(\frac{\Delta Y}{Y}\right)\left(\frac{X}{\Delta X}\right)=\left(\frac{\Delta Y}{\Delta X}\right)\left(\frac{X}{Y}\right)
$$

Como $\left(\frac{\Delta Y}{\Delta X}\right)$ é a definição de multiplicador $(\mu)$, pode-se obter a relação entre o multiplicador e a elasticidade da seguinte forma:

$$
\mu_{Y, X}=\frac{\varepsilon_{Y, X}}{\left(\frac{X}{Y}\right)}
$$

Um aspecto importante no processo de estimação de multiplicadores, em particular, em modelos dinâmicos é o que deve ser considerado como resposta do PIB à política fiscal. Segundo Spilimbergo et al. (2009) existem as seguintes medidas de multiplicador:

(i) O multiplicador de impacto $=\left[\frac{\Delta Y(t)}{\Delta G(t)}\right]$;

(ii) O multiplicador de horizonte $n=\left[\frac{\Delta Y(t+n)}{\Delta G(t)}\right]$;

(iii) O multiplicador de pico, definido como o impacto máximo dentro de qualquer horizonte $n=\max _{n}\left[\frac{\Delta Y(t+n)}{\Delta G(t)}\right]$;

(iv) O multiplicador cumulativo que soma toda a trajetória de mudanças no PIB e da política fiscal no horizonte $n=\left[\frac{\sum_{i=1}^{n} \Delta Y(t+i)}{\sum_{i=1}^{n} \Delta G(t+i)}\right]$.

Em modelos não lineares, os cálculos dos multiplicadores dinâmicos tendem a ser mais restritivos. Segundo Auerbach \& Gorodnichenko (2011), modelos não lineares têm a propriedade de transformarem os multiplicadores em dependentes do tempo ou dependentes de trajetória.

A dependência de trajetória do multiplicador fiscal ocorre porque uma vez adotado o choque fiscal a forma como a economia transitará de um regime ao outro irá afetar o cálculo do multiplicador. Exemplo: se um choque fiscal for simulado no momento em que a economia entrou em uma pequena recessão, ela sairá mais rápido dessa situação e, nesse caso, a trajetória do PIB refletirá a rápida transição de um regime para o outro.

Alternativamente, se o mesmo choque fiscal é simulado no vale de uma recessão, a trajetória do PIB poderá ser gerada apenas pelo processo gerador de dados do regime recessivo, gerando uma trajetória de PIB completamente diferente do caso anterior e, portanto, multiplicadores distintos. Enquanto a literatura ainda não apresentou uma boa resposta para essa questão, este artigo apresentará apenas multiplicadores de curto prazo (ou de impacto) por meio da transformação das elasticidades conforme equação (7). 


\section{Caracterização dos Regimes de Crescimento}

A tradição de analisar os ciclos econômicos a partir de modelos Markov Switching surgiu com Hamilton (1989) que analisa o ciclo da economia norte americana a partir de um modelo univariado com dois regimes, um de expansão e outro de recessão. Seus resultados mostram que o modelo MS data os ciclos econômicos de maneira muito próxima ao comitê do NBER, a referência utilizada para a datação de ciclos no EUA.

Uma aplicação importante dos modelos MS na literatura se deu para análise da política monetária. Clarida et al. (2000) identificaram um período de Grande Moderação na economia americana a partir dos anos 1980, durante a gestão de Paul Volcker no FED e atribuíram esse resultado ao padrão de política monetária adotado. Posteriormente, Sims \& Zha (2006) utilizaram os modelos MS para concluir que a Grande Moderação era explicada pela ausência de choques expressivos no período. ${ }^{12}$

A identificação dos ciclos econômicos a partir dos modelos MS é, portanto, uma etapa necessária para a validação da metodologia. Para o caso dos ciclos brasileiros, são analisadas três especificações que combinadas com dinâmicas de uma e duas defasagens se convertem em seis modelos. Esta diferenciação tem por objetivo aferir o efeito de dinâmicas distintas. Os resultados são resumidos na Tabela 1.

A primeira especificação analisou o modelo com dois estados e variância constante $(\mathrm{MS}(2,0,0,1))$. Esses dois estados são modelados na constante refletindo diferentes médias de crescimento caracterizando o ciclo em regimes de expansão e recessão. Enquanto esse modelo possui a vantagem de ser simples, sua aplicação para o PIB no Brasil indica a existência de um regime de recessão com poucas observações. Isso ocorre com uma ou duas defasagens, sendo que no modelo com uma defasagem existem evidências de que os resíduos são não normais. Para ambas as dinâmicas, o teste LR aponta evidências favoráveis ao modelo não linear.

A segunda especificação estendeu o modelo anterior para distintos regimes de variância tanto para uma defasagem quanto para duas defasagens (MS $(2,0,0,2))$. Nesse caso, os resultados são mais satisfatórios. Em ambos os modelos, a verossimilhança é maior e o critério de Akaike também indica em favor da sua seleção. Além dos testes de não linearidade apontarem pela melhor adequação do modelo não linear, o modelo também é mais satisfatório do ponto de vista dos resultados qualitativos já que os regimes recessivos são mais frequentes (cinco e seis episódios, respectivamente) e mais duradouros. Com efeito, essa evidência sugere que, no Brasil, a volatilidade pode ser mais importante do que a média de crescimento e, portanto, tende a dominar a evolução do ciclo econômico.

A terceira especificação avalia a idéia de que a volatilidade parece ser mais importante que a média de crescimento. Isso implica testar um modelo que diferencia os regimes apenas pela volatilidade, o que significa assumir que na especificação do modelo anterior a constante segue apenas um regime (MS $(1,0,0,2))$. Além da vantagem da parcimônia, esse modelo mantém algumas estatísticas de diagnóstico adequadas como a rejeição da hipótese de não normalidade dos resíduos bem como a adequação ao modelo não linear. Além disso, pelos critérios de verossimilhança e AIC, a especificação com uma

${ }^{12}$ Conclusão análoga é alcançada por Stock \& Watson (2003). 
defasagem parece superior às demais. Em ambos os casos, foram observados cinco episódios de elevada volatilidade com duração média de 2,8 trimestres. Segue daí que, de fato, a volatilidade tende a caracterizar a evolução do ciclo econômico brasileiro.

Os resultados indicam que o modelo MS-DIR não deve ser rejeitado para a descrição dos ciclos econômicos no Brasil. Nesse sentido serão considerados dois modelos que caracterizaram melhor o comportamento do ciclo econômico brasileiro (MS $(2,0,0,2)$-DIR $(2,0)$ e $\operatorname{MS}(1,0,0,2)$-DIR $(1,0))$. Uma forma adicional de validar essas duas especificações é comparar seus resultados com os indicados pelo Comitê de Datação de Ciclos - CODACE.

O CODACE identifica os ciclos econômicos, de forma análoga ao NBER, a partir da datação do trimestre em que ocorreu o pico do ciclo e da datação do trimestre em que ocorreu o seu vale. A partir daí, quantifica quantos trimestres durou a transição de uma fase à outra do ciclo econômico. Apesar da metodologia do CODACE ser diferente da elaborada a partir de modelos MS-DIR, vale comparar se os vales identificados correspondem minimamente aos períodos estabelecidos pelos modelos.

A Tabela 2 apresenta a comparação dos métodos. É possível perceber que o CODACE identificou um número menor de ciclos do que os modelos MS-DIR. Nesse caso, essa constatação atua em favor do modelo $\operatorname{MS}(1,0,0,2)$-DIR $(1,0)$ que possui menos ciclos que o seu concorrente. Isso reforça a preferência por essa especificação já que ela também apresentou estatísticas superiores.

Comparando de forma mais específica os resultados, o CODACE não identificou recessão no quarto trimestre de 1996 assim como a identificada em 2005. Existe uma divergência entre as especificações com relação ao ano de 2001. O modelo MS(2, 0, 0,2)-DIR(2,0) identificou uma recessão que durou dois trimestres, enquanto a especificação $\operatorname{MS}(1,0,0,2)$-DIR $(1,0)$ não a identificou. O CODACE identificou uma recessão de quatro trimestres nesse período.

Cumpre observar que os modelos também apresentaram identificação distinta no que se refere à duração da recessão. A recessão mais longa foi datada pelo CODACE entre 1997 e 1999, com duração de seis trimestres. Alternativamente, os modelos encontraram recessões com duração de um trimestre em 1996 e 2003. A duração média de cada recessão pela cronologia do CODACE é de quatro trimestres enquanto no modelo $\operatorname{MS}(2,0,0,2)$-DIR $(2,0)$ possui duração média de 2,5 trimestres e no modelo MS $(1,0,0,2)$-DIR $(1,0)$ possui duração média de 2,8 trimestres.

\section{Evidências de multiplicadores fiscais}

A partir das especificações previamente selecionadas para o ciclo econômico brasileiro pode-se avaliar o tamanho dos multiplicadores fiscais. A Tabela A.1, no Apêndice, apresenta as estimativas do $\operatorname{MS}(2,0,0,2)-\operatorname{DIR}(2,0)$ incluindo as três variáveis fiscais e alternando várias especificações para entender qual modelo é mais adequado.

Existem três indicações importantes nesse conjunto de resultados. O primeiro é que o consumo do governo não foi significativo em nenhuma especificação. O segundo é que apenas as defasagens mais longas da carga tributária líquida são significativas e com o sinal esperado, notadamente a segunda defasagem. O terceiro é que o investimento público é significativo em todas as especificações. De acordo com os critérios estatísticos, o modelo que parece 
Tabela 1: Diagnóstico e seleção de modelos MS-DIR

\begin{tabular}{|c|c|c|c|c|c|}
\hline $\begin{array}{l}\text { Especificação do MS- } \\
\text { DIR }\end{array}$ & Log-Likelihood & AIC & $\begin{array}{l}\text { LR-test ( } \mathrm{p} \text {-valor } \\
\text { limite superior) }\end{array}$ & Normalidade & Descrição \\
\hline $\operatorname{MS}(2,0,0,1)-\operatorname{DIR}(1,0)$ & $-104,0839$ & 3,3056 & $\begin{array}{l}9,4117^{*} \\
(0,0243)\end{array}$ & $\begin{array}{l}15,870^{*} \\
(0,0004)\end{array}$ & $\begin{array}{l}\text { Regime recessivo com crescimento médio nega- } \\
\text { tivo. Quatro episódios com duração de um tri- } \\
\text { mestre cada. }\end{array}$ \\
\hline $\operatorname{MS}(2,0,0,1)-\operatorname{DIR}(2,0)$ & $-93,6712$ & 3,0668 & $\begin{array}{r}17,151^{*} \\
(0,0007)\end{array}$ & $\begin{array}{l}0,5583^{*} \\
(0,7564)\end{array}$ & $\begin{array}{l}\text { Regime recessivo com média de crescimento mé- } \\
\text { dio negativo de }-2.57 \text { por trimestre. Cinco episó- } \\
\text { dios com duração de um trimestre cada. }\end{array}$ \\
\hline $\operatorname{MS}(2,0,0,2)-\operatorname{DIR}(1,0)$ & $-94,7795$ & 3,0842 & $\begin{array}{l}28,020^{*} \\
(0,0000)\end{array}$ & $\begin{array}{l}1,9424^{*} \\
(0,3786)\end{array}$ & $\begin{array}{l}\text { Regime recessivo com crescimento médio nega- } \\
\text { tivo próximo a zero e elevada volatilidade. Cinco } \\
\text { episódios com duração média de } 3 \text { trimestres } \\
\text { cada. }\end{array}$ \\
\hline $\operatorname{MS}(2,0,0,2)-\operatorname{DIR}(2,0)$ & $-90,0071$ & 3,0156 & $\begin{array}{l}24,479^{*} \\
(0,0001)\end{array}$ & $\begin{array}{l}1,7106^{*} \\
(0,4252)\end{array}$ & $\begin{array}{l}\text { Regime recessivo com crescimento médio nega- } \\
\text { tivo próximo a zero e elevada volatilidade. Seis } \\
\text { episódios com duração média de } 2.5 \text { trimestres } \\
\text { cada. }\end{array}$ \\
\hline $\operatorname{MS}(1,0,0,2)-\operatorname{DIR}(1,0)$ & $-91,5005$ & 3,0000 & $\begin{array}{l}21,802^{*} \\
(0,0004)\end{array}$ & $\begin{array}{l}2,7577^{*} \\
(0,2519)\end{array}$ & $\begin{array}{l}\text { Regime recessivo com elevada volatilidade. } \\
\text { Cinco episódios com duração média de } 2.8 \text { tri- } \\
\text { mestre. }\end{array}$ \\
\hline $\operatorname{MS}(1,0,0,2)-\operatorname{DIR}(2,0)$ & $-91,4977$ & 3,3007 & $\begin{array}{l}21,498^{*} \\
(0,0005)\end{array}$ & $\begin{array}{l}2,7321^{*} \\
(0,2551)\end{array}$ & $\begin{array}{l}\text { Regime recessivo com elevada volatilidade. } \\
\text { Cinco episódios com duração média de } 2.8 \text { tri- } \\
\text { mestre. }\end{array}$ \\
\hline
\end{tabular}

Fonte: Obtido a partir do software OxMetric-PcGive. 
Tabela 2: Datação dos ciclos econômicos

\begin{tabular}{|c|c|c|c|c|c|c|c|c|c|c|}
\hline \multicolumn{4}{|c|}{$\begin{array}{l}\text { MS(2,0,0,2)-DIR(2,0)-Regime de recessão com ele- } \\
\text { vada volatilidade }\end{array}$} & \multicolumn{4}{|c|}{$\begin{array}{l}\text { MS }(1,0,0,2) \text {-DIR }(1,0) \text {-Regime com elevada volatili- } \\
\text { dade }\end{array}$} & \multicolumn{3}{|c|}{ CODACE - Cronologia do ciclo } \\
\hline Início & Fim & Trimestres & $\begin{array}{l}\text { Probabilidade } \\
\text { média }\end{array}$ & Início & Fim & Trimestres & $\begin{array}{l}\text { Probabilidade } \\
\text { média }\end{array}$ & Pico & Vale & $\begin{array}{l}\text { Do pico ao vale } \\
\text { (em trimestres) }\end{array}$ \\
\hline $1996(4)$ & $1996(4)$ & 1 & 1 & $1996(4)$ & $1996(4)$ & 1 & 1 & n.a. & n.a & n.a \\
\hline $1998(1)$ & $1998(4)$ & 4 & 0,993 & 1998(1) & $1998(4)$ & 4 & 0,987 & $1997(4)$ & $1999(1)$ & 6 \\
\hline $2001(2)$ & 2001(3) & 2 & 0,632 & n.a & n.a & n.a & n.a & 2001(1) & $2001(4)$ & 4 \\
\hline $2003(1)$ & $2003(1)$ & 1 & 0,996 & $2003(1)$ & $2003(1)$ & 1 & 0,986 & $2002(4)$ & $2003(2)$ & 3 \\
\hline $2005(1)$ & $2005(4)$ & 4 & 0,825 & $2005(1)$ & $2005(4)$ & 4 & 0,833 & n.a. & n.a & n.a \\
\hline 2008(4) & $2009(2)$ & 3 & 0,889 & 2008(4) & $2009(3)$ & 4 & 0,808 & $2008(3)$ & $2009(1)$ & 3 \\
\hline
\end{tabular}


ser o mais adequado possui o consumo do governo e o investimento público sem defasagens (modelo 5). Alternativamente, também é possível considerar o modelo com uma defasagem para o consumo do governo e o investimento público (modelo 2). Ambos possuem resultados muito próximos. Eles apontam para multiplicadores do investimento público entre 1,4 e 1,5 e multiplicadores da carga tributária líquida em torno de -0,28 (Tabela 3).

A Tabela A.2, no Apêndice, apresenta os resultados do modelo MS (1, 0, 0, 2)$\operatorname{DIR}(1,0)$ com as mesmas especificações para as variáveis fiscais testadas anteriormente. Assim como antes, a carga tributária líquida é significativa e com o sinal esperado apenas na segunda defasagem. A diferença mais marcante em relação ao modelo anterior é que o consumo do governo passou a ser significativo ao passo que o investimento público não. Esses modelos apontam para multiplicadores do consumo do governo em torno de 0,6 e para a carga tributária líquida entre -0,21 e -0,27 (Tabela 3). Em comparação, deve-se notar que os critérios estatísticos tendem a mostrar melhor adequação do modelo $\operatorname{MS}(2,0,0,2)-\operatorname{DIR}(2,0)$, pois possui maior verossimilhança e menor AIC.

Um aspecto importante a ser investigado é como se comportam os multiplicadores fiscais ao longo do ciclo econômico. Para avaliar isso, as duas especificações selecionadas foram reestimadas permitindo que os multiplicadores fossem distintos conforme o ciclo econômico (Tabelas A.3 e A.4). Os resultados em ambas as especificações são idênticos e mostram que: (i) o consumo do governo não é significativo em nenhum regime, (ii) o investimento público e a carga tributária líquida são significativos no regime com menor volatilidade e maior crescimento médio não sendo significativo no outro regime de maior volatilidade. O multiplicador obtido para o investimento público situa-se entre 1,6 e 1,7 enquanto o multiplicador da carga tributária líquida em torno de $-0,29$ durante o regime de menor volatilidade (Tabela 4).

Cabe ressaltar que enquanto o multiplicador da carga tributária líquida foi robusto em várias especificações, o multiplicador do consumo do governo não foi significativo. O caso do investimento público é peculiar. Seus resultados parecem robustos apresentando multiplicadores maiores que a unidade. No entanto, os resultados indicaram significância desse multiplicador no regime com menor volatilidade independente do regime de crescimento. Nesse caso, surgem como potenciais causas o fato da política fiscal ter sido pró-cíclica na maior parte do período estudado (Schettini et al. 2011) ou que em regimes de elevada volatilidade a relação entre política fiscal e crescimento seja ainda mais complexa. ${ }^{13}$

Tabela 3: Multiplicadores Fiscais

\begin{tabular}{lccccc}
\hline \multirow{2}{*}{ Variáveis fiscais } & Peso no PIB a & \multicolumn{2}{c}{ MS(2,0,0,2)-DIR(2,0) } & \multicolumn{2}{c}{ MS(1,0,0,2)-DIR(1,0) } \\
\cline { 3 - 6 } & preços de 1995 & Modelo 2 & Modelo 5 & Modelo 2 & Modelo 5 \\
\hline Consumo do governo & 0,19927 & n.a & n.a & 0,66 & 0,59 \\
Investimento público & 0,02106 & 1,42 & 1,52 & n.a & n.a \\
Carga tributária & 0,21103 & $-0,28$ & $-0,27$ & $-0,21$ & $-0,27$ \\
líquida & & & & & \\
\hline
\end{tabular}

\footnotetext{
${ }^{13}$ Sobre a relação entre crescimento e volatilidade ver Aghion \& Banerjee (2005).
} 
Tabela 4: Comportamento dos multiplicadores fiscais no ciclo econômico

\begin{tabular}{lccccc}
\hline \multirow{2}{*}{$\begin{array}{l}\text { Variáveis } \\
\text { fiscais }\end{array}$} & $\begin{array}{l}\text { Peso no PIB a } \\
\text { preços de }\end{array}$ & \multicolumn{2}{c}{ MS(2,0,0,2)-DIR(2,0)-Modelo 2 } & \multicolumn{2}{c}{ MS(1,0,0,2)-DIR(1,0)-Modelo 2 } \\
\cline { 3 - 7 } & 1995 & $\begin{array}{l}\text { Elevada } \\
\text { dade }\end{array}$ & $\begin{array}{l}\text { volatili- } \\
\text { daixa } \\
\text { dade }\end{array}$ & $\begin{array}{l}\text { volatili- } \\
\text { dade }\end{array}$ & $\begin{array}{l}\text { volatili- } \\
\text { daixa } \\
\text { dade }\end{array}$ \\
\hline $\mathrm{g}$ & 0,19927 & n.a & n.a & n.a & n.a \\
$\mathrm{i}$ & 0,02106 & n.a & 1,71 & n.a & 1,61 \\
$\mathrm{ctl}$ & 0,21103 & n.a & $-0,28$ & n.a & $-0,29$ \\
\hline
\end{tabular}

\section{Conclusões}

O impacto da política fiscal sobre o crescimento econômico tem sido revisitado nos últimos anos em decorrência do renovado interesse dos economistas em reavaliar esse instrumento de política em circunstâncias de restrição da política monetária. Com efeito, a literatura passou por forte impulso após a divulgação do "The job impact of the American Recovery and Reinvestment Plan" que conclui por multiplicadores elevados.

Tais multiplicadores foram objeto de calorosa controvérsia dando impulso a uma renovada literatura que buscou estabelecer novas e melhores evidências empíricas. Diante dessas evidências recentes, a ideia keynesiana de que multiplicadores fiscais podem ser elevados em momentos de recessão voltou a ganhar corpo.

Este artigo estimou multiplicadores fiscais para a economia brasileira detalhando como dependem do ciclo econômico e diferenciando o impacto entre consumo do governo, investimentos públicos e carga tributária líquida concluindo em favor da evidência de que os multiplicadores possuem comportamento diferenciado ao longo do ciclo.

As evidências empíricas indicam que o ciclo econômico no Brasil é caracterizado por períodos de baixa ou elevada volatilidade. Com efeito, os multiplicadores mostraram significância estatística em períodos de baixa volatilidade. A carga tributária líquida apresentou multiplicador fiscal robusto da ordem de $-0,2$ a $-0,3$ enquanto o investimento público apresentou multiplicador maior que a unidade, entre 1,4 e 1,7. O multiplicador fiscal do consumo do governo não foi significativo. Duas potenciais explicações para o fato de que os multiplicadores se mostraram relevantes no período de baixa volatilidade são: (i) que a política fiscal brasileira foi pró cíclica na maior parte do período e, (ii) que na presença de regimes de volatilidade a relação entre a política fiscal e o crescimento pode ser mais complexa. Essas duas explicações remetem à continuidade dessa linha de pesquisa no futuro.

\section{Referências Bibliográficas}

Aghion, P. \& Banerjee, A. (2005), Volatility and growth, Clarendon Lectures in Economics.

Almunia, M., Bénétrix, A. \& Eichengreen, B. (2009), 'From great depression to great credit crisis: similarities, differences and lessons', $50^{\circ}$ Economic policy panel meeting, University of Tilburg.

Auerbach, A. \& Gorodnichenko, Y. (2011), Measuring the output responses to fiscal policy, working paper 16311, NBER. 
Auerbach, A. \& Gorodnichenko, Y. (2012), Fiscal multipliers in recession and expansion, Fiscal policy after the financial crisis.

Bernstein, J. \& Romer, C. (2009), 'The job impact of the american recovery and reinvestment plan'.

URL: $\quad<h t t p: / / w w w . e c o n o m y . c o m / m a r k-z a n d i / d o c u m e n t s / T h e \_J o b_{-}-$ Impact_of_the_American_Recovery_and_Reinvestment_Plan.pdf $>$

Blanchard, O. \& Perroti, R. (2002), 'An empirical characterization of the dynamic effects of changes in government spending and taxes on output', Quarterly Journal of Economics 117(4), 1329-1368.

Cavalcanti, M. A. \& Silva, N. (2010), 'Dívida pública, política fiscal e nível de atividade: Uma abordagem var para o brasil no período 1995-2008', Revista de Economia Aplicada 14(4), 391-418.

Clarida, R., Gali, J. \& Gertler, M. (2000), 'Monetary policy rules and macroeconomic stability: Evidence and some theory', Quarterly Journal of Economics 115(1), 147-180.

Cogan, J., Cwik, T., Taylor, J. \& Wieland, V. (2010), 'New keynesian versus old keynesian government spending multipliers', Journal of Economics Dynamics and Control 34(3), 281-295.

Davies, R. B. (1987), 'Hypothesis testing when a nuisance parameter is present only under the alternative', Biometrica 74, 33-43.

Dos Santos, C. H. (2008), Uma metodologia simplificada de estimação da carga tributária líquida brasileira trimestral no período 1995-2007, Texto para discussão 1359, IPEA.

Dos Santos, C. H., Orair, R., Gobetti, S., Ferreira, A., Silva, H. \& Britto, J. M. (2011), Uma metodologia de estimação da formação bruta de capital fixo das administrações públicas brasileiras em níveis mensais para o período 20022010, Texto para discussão 1660, IPEA.

Eggertsson, G. \& Krugman, P. (2010), 'Debt, deleveraging, and the liquidity trap: A fisher-minsky-koo approach', Paper presented at FED San Francisco: Monetary Policy at the Zero Lower Bond.

URL: <http://www.frbsf.org/economics/conferences/1102/PKGE_Feb14.pdf>

FMI (2010), Fiscal monitor: Balancing fiscal policy risks, Technical report, World Economic and Financial Surveys. Washington, DC.

Gali, J., López-Salido, D. \& Vallés, J. (2007), 'Understanding the effects of government spending on consumption', Journal of the European Economic Association $\mathbf{5}(1), 227-270$.

Hall, R. (2009), 'By how much does gdp rise if the government buys more output?', Brooking Papers on Economic Activity pp. 183-231.

Hamilton, J. (1989), 'A new approach to the economic analysis of nonstationary time series and the business cycle', Econometrica 57(2), 357-384.

Krenn, R. \& Gordon, R. (2010), The end of the great depression1939-41: Policy contributions and fiscal multiplires, working paper 16380, NBER. 
Lawrence, C. T. \& Tits, A. L. (2001), 'A computationally efficient feasible sequential quadratic programming algorithm', SIAM Journal of Optimization 11, 1092-1118.

Mittnik, S. \& Semmler, W. (2011), Regime dependence of the fiscal multiplier, Paper presented at The long term consequences of short run fluctuactions.

Mountford, A. \& Uhlig, H. (2009), 'What are the effects of fiscal policy shocks?', Journal of Applied Econometrics 24(6), 960-992.

Peres, M. A. \& Ellery, R. (2009), 'Efeitos dinâmicos dos choques fiscais do governo central no pib', Pesquisa e Planejamento Econômico 39(2), 159-206.

Perroti, R. (2008), 'In search of the transmission mechanism of fiscal policy', NBER Macroeconomics Annual 22, 169-226.

Pires, M. C. C. (2011), 'Controvérsias recentes sobre multiplicadores fiscais', BID, Multiplicadores fiscais no Brasil. Brasília- DF.

Posen, A. (1998), 'Restoring japan's economic growth. policy analyses in international economics', Institute for International Economics .

Ramey, V. (2011), 'Identifying government spending shocks: It's all in the timing', Quarterly Journal of Economics 126(1), 1-50.

Schettini, P. B., Gouvêa, R. R., Orair, R. O. \& Gobetti, S. W. (2011), 'Resultado primário e impulso fiscal: Uma aplicação para as administrações públicas no brasil - 1997-2010', Pesquisa e Planejamento Econômico 41(2), 233-285.

Sims, C. \& Zha, T. (2006), 'Were there regimes switches in u.s. monetary policy?', American Economic Review 96(1), 54-81.

Spilimbergo, A., Symanski, S. \& Schindler, M. (2009), Fiscal multipliers, Technical report, IMF Staff Position Note, IMF.

Stock, J. H. \& Watson, M. W. (2003), Has the business cycle changed and why?, Vol. 17, NBER Macroeconomics Annual. MIT Press.

Taylor, J. (2011), 'An empirical analysis of the revival of fiscal activism in the 2000's', Journal of Economic Literature 49(3), 686-702.

Teräsvirta, T. (2006), Univariate nonlinear time series models, Palgrave Handbook of Econometrics. Palgrave MacMilan, pp. 396-424.

Woodford, M. (2010), Simple analytics of the government multiplier, Technical report, Presented at "Fiscal stabilization policy", Allied Social Science Associations, Atlanta-Georgia. 


\section{Apêndice A}

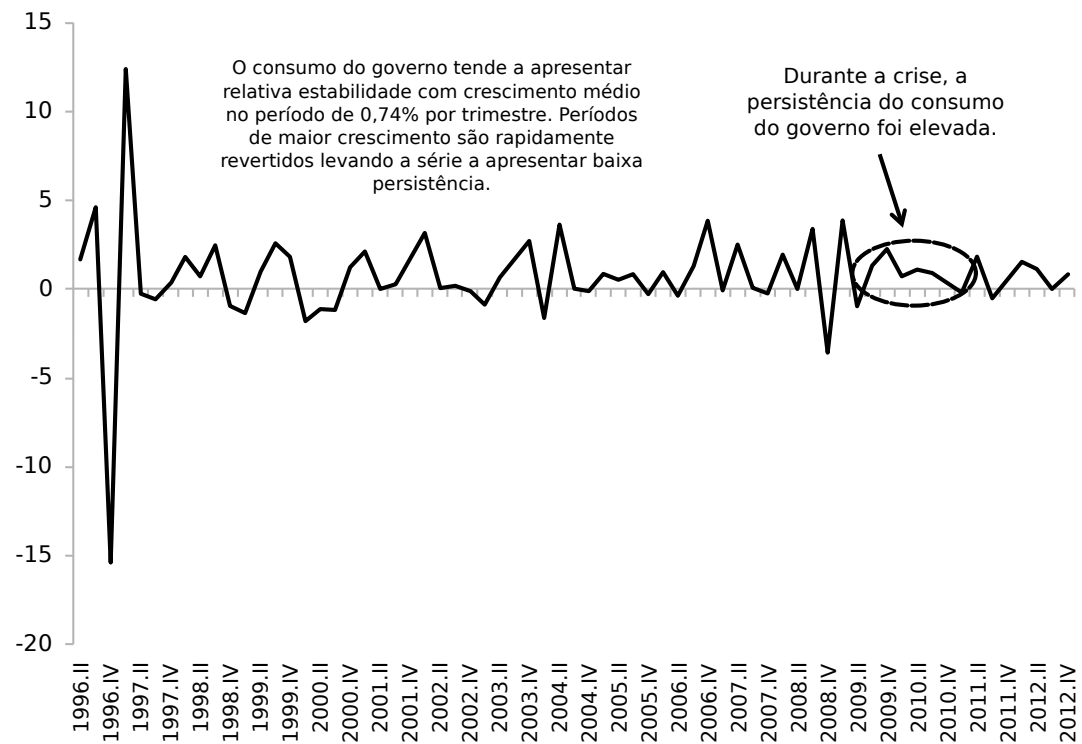

Fonte: 1IBGE.

Figura A.1: Evolução da taxa de crescimento do consumo do governo

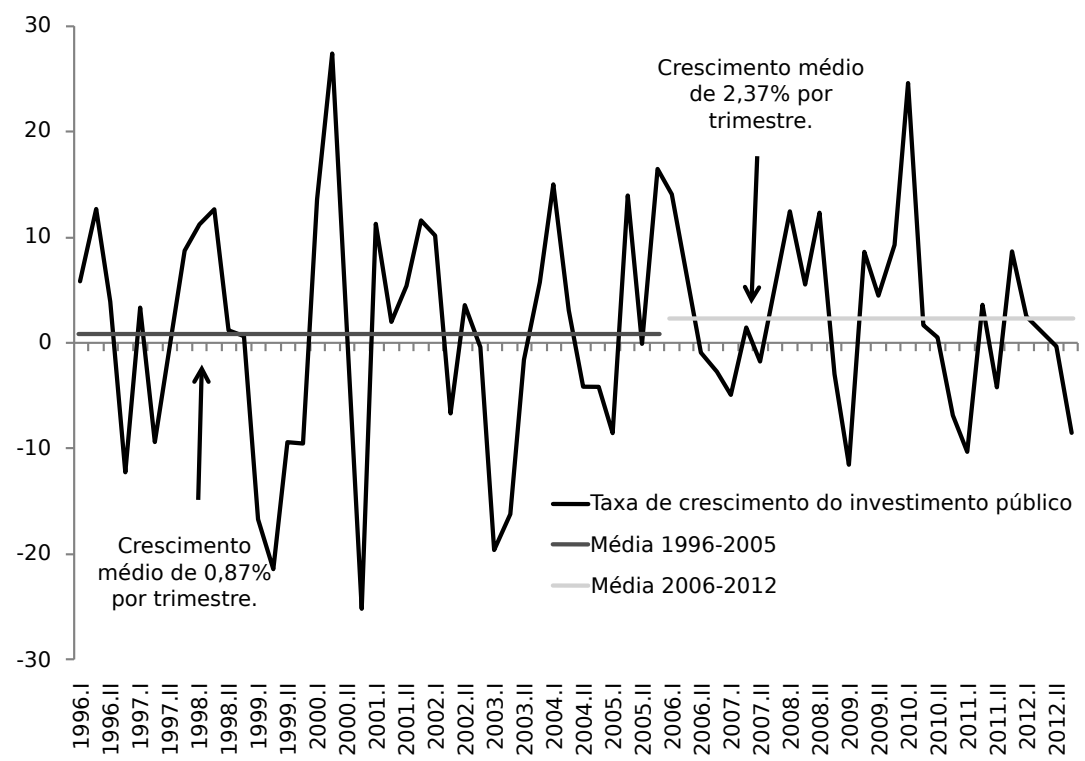

Fonte: Dos Santos et al. (2011).

Figura A.2: Evolução da taxa de crescimento do investimento público 


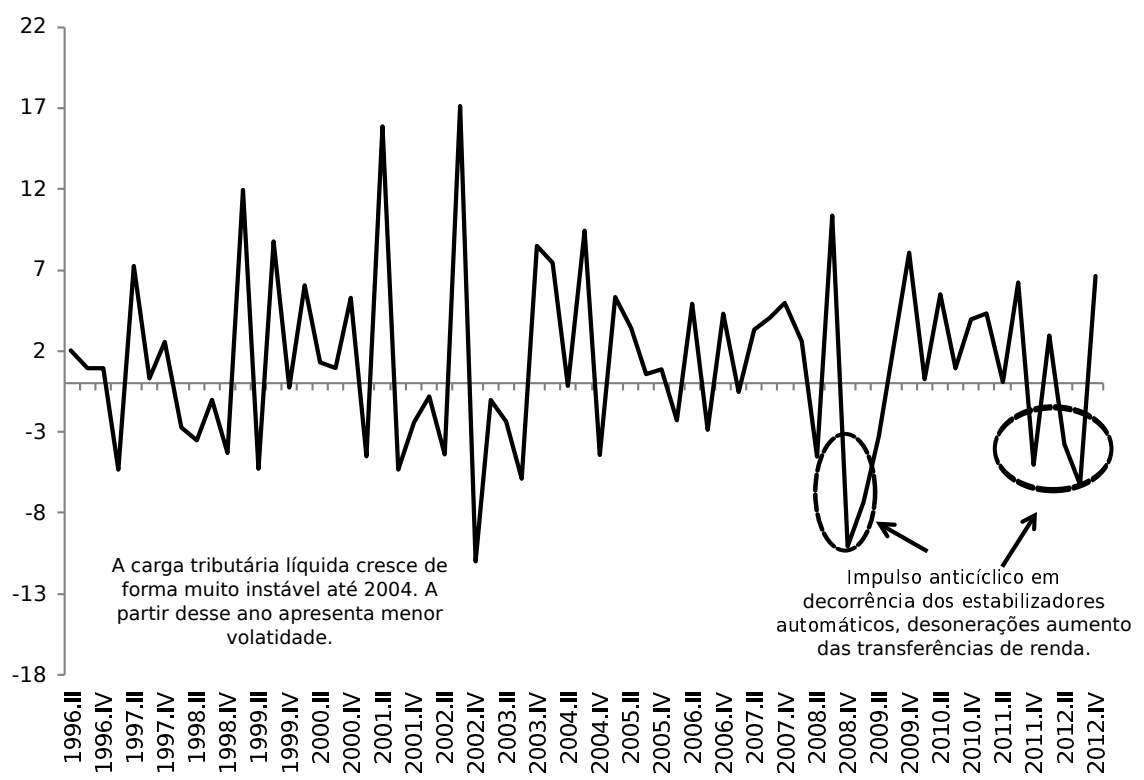

Fonte: Dos Santos (2008).

Figura A.3: Evolução da taxa de crescimento da carga tributária líquida 
Tabela A.1: Estimativas do modelo MS(2,0,0,2)-DIR(2,0)

\begin{tabular}{|c|c|c|c|c|c|}
\hline & Modelo 1 & Modelo 2 & Modelo 3 & Modelo 4 & Modelo 5 \\
\hline c (regime 1$)$ & $\begin{array}{r}-0,729 \\
(0,696)\end{array}$ & $\begin{array}{r}-0,494 \\
(0,661)\end{array}$ & $\begin{array}{r}-0,024 \\
(0,419)\end{array}$ & $\begin{array}{r}-0,064 \\
(0,453)\end{array}$ & $\begin{array}{r}-0,481 \\
(0,570)\end{array}$ \\
\hline c (regime 2) & $\begin{array}{l}0,734^{*} \\
(0,160)\end{array}$ & $\begin{array}{l}0,786^{*} \\
(0,163)\end{array}$ & $\begin{array}{l}1,155^{*} \\
(0,214)\end{array}$ & $\begin{array}{l}0,696^{*} \\
(0,101)\end{array}$ & $\begin{array}{l}0,822^{*} \\
(0,120)\end{array}$ \\
\hline$y(-1)$ & $\begin{array}{l}0,131 \\
(0,109)\end{array}$ & $\begin{array}{l}0,351^{*} \\
(0,080)\end{array}$ & $\begin{array}{l}0,225 \\
(0,161)\end{array}$ & $\begin{array}{l}0,517^{*} \\
(0,076)\end{array}$ & $\begin{array}{l}0,375^{*} \\
(0,075)\end{array}$ \\
\hline$y(-2)$ & $\begin{array}{c}-0,212^{*} \\
(0,083)\end{array}$ & $\begin{array}{r}-0,051 \\
(0,073)\end{array}$ & $\begin{array}{r}-0,141 \\
(0,079)\end{array}$ & $\begin{array}{r}-0,046 \\
(0,077)\end{array}$ & $\begin{array}{r}-0,069 \\
(0,067)\end{array}$ \\
\hline g & $\begin{array}{l}0,159^{*} \\
(0,037)\end{array}$ & $\begin{array}{l}0,071 \\
(0,057)\end{array}$ & $\begin{array}{l}0,018 \\
(0,080)\end{array}$ & n.a. & $\begin{array}{l}0,053 \\
(0,054)\end{array}$ \\
\hline $\mathrm{g}(-1)$ & $\begin{array}{l}0,059 \\
(0,036)\end{array}$ & $\begin{array}{l}0,030 \\
(0,045)\end{array}$ & $\begin{array}{r}-0,004 \\
(0,041)\end{array}$ & $\begin{array}{r}-0,006 \\
(0,037)\end{array}$ & n.a. \\
\hline $\mathrm{i}$ & $\begin{array}{l}0,025^{*} \\
(0,010)\end{array}$ & $\begin{array}{l}0,030^{*} \\
(0,015)\end{array}$ & $\begin{array}{l}0,028^{*} \\
(0,011)\end{array}$ & n.a. & $\begin{array}{l}0,032^{*} \\
(0,009)\end{array}$ \\
\hline $\mathrm{i}(-1)$ & $\begin{array}{l}0,009 \\
(0,010)\end{array}$ & $\begin{array}{l}0,003 \\
(0,014)\end{array}$ & $\begin{array}{l}0,008 \\
(0,011)\end{array}$ & $\begin{array}{l}0,014 \\
(0,008)\end{array}$ & n.a. \\
\hline ctl & $\begin{array}{l}0,042^{*} \\
(0,019)\end{array}$ & n.a. & n.a. & n.a. & n.a. \\
\hline $\operatorname{ctl}(-1)$ & $\begin{array}{l}0,073^{*} \\
(0,019)\end{array}$ & n.a. & n.a. & n.a. & n.a. \\
\hline $\operatorname{ctl}(-2)$ & n.a. & $\begin{array}{c}-0,059^{*} \\
(0,014)\end{array}$ & n.a. & $\begin{array}{c}-0,041^{*} \\
(0,014)\end{array}$ & $\begin{array}{c}-0,057^{*} \\
(0,014)\end{array}$ \\
\hline $\operatorname{ctl}(-3)$ & n.a. & $\begin{array}{c}-0,005 \\
(0,016)\end{array}$ & $\begin{array}{c}0,0001 \\
(0,020)\end{array}$ & $\begin{array}{c}-0,017 \\
(0,014)\end{array}$ & $\begin{array}{c}-0,001 \\
(0,014)\end{array}$ \\
\hline $\operatorname{ctl}(-4)$ & n.a. & n.a. & $\begin{array}{r}-0,005 \\
(0,014)\end{array}$ & n.a. & n.a. \\
\hline sigma (regime 1$)$ & $\begin{array}{l}1,576^{*} \\
(0,399)\end{array}$ & $\begin{array}{l}1,718^{*} \\
(0,360)\end{array}$ & $\begin{array}{l}1,310^{*} \\
(0,206)\end{array}$ & $\begin{array}{l}1,897^{*} \\
(0,344)\end{array}$ & $\begin{array}{l}1,701^{*} \\
(0,344)\end{array}$ \\
\hline sigma (regime 2) & $\begin{array}{l}0,546^{*} \\
(0,068)\end{array}$ & $\begin{array}{l}0,467^{*} \\
(0,094)\end{array}$ & $\begin{array}{l}0,392^{*} \\
(0,108)\end{array}$ & $\begin{array}{l}0,374^{*} \\
(0,089)\end{array}$ & $\begin{array}{l}0,472^{*} \\
(0,073)\end{array}$ \\
\hline$p_{-}(1 \mid 1)$ & $\begin{array}{l}0,515^{*} \\
(0,253)\end{array}$ & $\begin{array}{l}0,563^{*} \\
(0,284)\end{array}$ & $\begin{array}{l}0,695^{*} \\
(0,163)\end{array}$ & $\begin{array}{l}0,562^{*} \\
(0,174)\end{array}$ & $\begin{array}{l}0,547^{*} \\
(0,211)\end{array}$ \\
\hline$p_{-}(1 \mid 2)$ & $\begin{array}{l}0,115 \\
(0,065)\end{array}$ & $\begin{array}{l}0,136 \\
(0,085)\end{array}$ & $\begin{array}{l}0,259^{*} \\
(0,097)\end{array}$ & $\begin{array}{l}0,214 \\
(0,130)\end{array}$ & $\begin{array}{l}0,145 \\
(0,077)\end{array}$ \\
\hline AIC & 2,872 & 2,849 & 3,082 & 2,919 & 2,834 \\
\hline Ver, & $-79,348$ & $-77,168$ & $-83,089$ & $-79,933$ & $-77,268$ \\
\hline Teste LR ${ }^{* *}$ & $\begin{array}{l}23,918 \\
(0,0002)\end{array}$ & $\begin{array}{l}31,719 \\
(0,0000)\end{array}$ & $\begin{array}{l}18,849 \\
(0,0008)\end{array}$ & $\begin{array}{c}32,733 \\
(0,0000)\end{array}$ & $\begin{array}{l}30,284 \\
(0,0000)\end{array}$ \\
\hline
\end{tabular}

${ }^{*}$ Significância estatística de $5 \%$.

** Desvio padrão em parêntesis, exceto para o teste LR em que foi reportado o p-valor.

Os Modelos 2 e 5 possuem as melhores adequação estatística. 
Tabela A.2: Estimativas do modelo MS(1,0,0,2)-DIR(1,0)

\begin{tabular}{|c|c|c|c|c|c|}
\hline & Modelo 1 & Modelo 2 & Modelo 3 & Modelo 4 & Modelo 5 \\
\hline c & $\begin{array}{l}0,434^{*} \\
(0,125)\end{array}$ & $\begin{array}{l}0,476^{*} \\
(0,140)\end{array}$ & $\begin{array}{l}0,466^{*} \\
(0,151)\end{array}$ & $\begin{array}{l}0,628^{*} \\
(0,107)\end{array}$ & $\begin{array}{l}0,487^{*} \\
(0,143)\end{array}$ \\
\hline$y(-1)$ & $\begin{array}{l}0,175 \\
(0,115)\end{array}$ & $\begin{array}{l}0,484^{*} \\
(0,105)\end{array}$ & $\begin{array}{l}0,483^{*} \\
(0,120)\end{array}$ & $\begin{array}{l}0,509^{*} \\
(0,075)\end{array}$ & $\begin{array}{l}0,510^{*} \\
(0,108)\end{array}$ \\
\hline $\mathrm{g}$ & $\begin{array}{l}0,168^{*} \\
(0,057)\end{array}$ & $\begin{array}{l}0,132^{*} \\
(0,056)\end{array}$ & $\begin{array}{l}0,076 \\
(0,062)\end{array}$ & n.a. & $\begin{array}{l}0,117^{*} \\
(0,056)\end{array}$ \\
\hline$g(-1)$ & $\begin{array}{l}0,078^{*} \\
(0,038)\end{array}$ & $\begin{array}{l}0,030 \\
(0,036)\end{array}$ & $\begin{array}{l}0,025 \\
(0,039)\end{array}$ & $\begin{array}{l}0,007 \\
(0,033)\end{array}$ & n.a. \\
\hline $\mathrm{i}$ & $\begin{array}{l}0,013 \\
(0,010)\end{array}$ & $\begin{array}{l}0,006 \\
(0,009)\end{array}$ & $\begin{array}{l}0,001 \\
(0,011)\end{array}$ & n.a. & $\begin{array}{l}0,009 \\
(0,009)\end{array}$ \\
\hline $\mathrm{i}(-1)$ & $\begin{array}{c}0,007 \\
(0,010)\end{array}$ & $\begin{array}{l}0,009 \\
(0,008)\end{array}$ & $\begin{array}{l}0,003 \\
(0,008)\end{array}$ & $\begin{array}{l}0,011 \\
(0,008)\end{array}$ & n.a. \\
\hline ctl & $\begin{array}{l}0,036^{*} \\
(0,018)\end{array}$ & n.a. & n.a. & n.a. & n.a. \\
\hline $\operatorname{ctl}(-1)$ & $\begin{array}{l}0,069^{*} \\
(0,018)\end{array}$ & n.a. & n.a. & n.a. & n.a. \\
\hline $\operatorname{ctl}(-2)$ & n.a. & $\begin{array}{c}-0,060^{*} \\
(0,014)\end{array}$ & n.a. & $\begin{array}{c}-0,044^{*} \\
(0,014)\end{array}$ & $\begin{array}{c}-0,057^{*} \\
(0,015)\end{array}$ \\
\hline $\operatorname{ctl}(-3)$ & n.a. & $\begin{array}{r}-0,024 \\
(0,013)\end{array}$ & $\begin{array}{r}-0,010 \\
(0,016)\end{array}$ & $\begin{array}{r}-0,024 \\
(0,012)\end{array}$ & $\begin{array}{r}-0,021 \\
(0,014)\end{array}$ \\
\hline $\operatorname{ctl}(-4)$ & n.a. & n.a. & $\begin{array}{r}-0,004 \\
(0,015)\end{array}$ & n.a. & n.a. \\
\hline sigma (regime 1 ) & $\begin{array}{l}1,973^{*} \\
(0,415)\end{array}$ & $\begin{array}{l}2,218^{*} \\
(0,510)\end{array}$ & $\begin{array}{l}2,081^{*} \\
(0,445)\end{array}$ & $\begin{array}{l}2,086^{*} \\
(0,392)\end{array}$ & $\begin{array}{l}2,182^{*} \\
(0,505)\end{array}$ \\
\hline sigma (regime 2 ) & $\begin{array}{l}0,483^{*} \\
(0,059)\end{array}$ & $\begin{array}{l}0,491^{*} \\
(0,067)\end{array}$ & $\begin{array}{l}0,515^{*} \\
(0,080)\end{array}$ & $\begin{array}{l}0,411^{*} \\
(0,080)\end{array}$ & $\begin{array}{l}0,472^{*} \\
(0,067)\end{array}$ \\
\hline$p_{-}(1 \mid 1)$ & $\begin{array}{l}0,673^{*} \\
(0,016)\end{array}$ & $\begin{array}{l}0,672^{*} \\
(0,170)\end{array}$ & $\begin{array}{l}0,645^{*} \\
(0,166)\end{array}$ & $\begin{array}{l}0,614^{*} \\
(0,167)\end{array}$ & $\begin{array}{l}0,678^{*} \\
(0,169)\end{array}$ \\
\hline$p_{-}(1 \mid 2)$ & $\begin{array}{l}0,115^{*} \\
(0,060)\end{array}$ & $\begin{array}{l}0,093 \\
(0,061)\end{array}$ & $\begin{array}{l}0,129 \\
(0,072)\end{array}$ & $\begin{array}{l}0,168 \\
(0,094)\end{array}$ & $\begin{array}{c}0,090 \\
(0,058)\end{array}$ \\
\hline AIC & 2,927 & 2,875 & 3,069 & 2,901 & 2,843 \\
\hline Ver, & $-80,192$ & $-78,562$ & $-84,684$ & $-81,387$ & $-79,562$ \\
\hline Teste LR** & $\begin{array}{l}20,642 \\
(0,0007)\end{array}$ & $\begin{array}{l}26,605 \\
(0,0000)\end{array}$ & $\begin{array}{l}16,576 \\
(0,0044)\end{array}$ & $\begin{array}{l}30,431 \\
(0,0000)\end{array}$ & $\begin{array}{l}26,090 \\
(0,0000)\end{array}$ \\
\hline
\end{tabular}

\footnotetext{
${ }^{*}$ Significância estatística de $5 \%$.

${ }^{* *}$ Desvio padrão em parêntesis, exceto para o teste LR em que foi reportado o p-valor.
}

Os Modelos 2 e 5 possuem as melhores adequação estatística. 
Tabela A.3: Estimativas com multiplicadores fiscais dependentes do regime no modelo $\mathrm{MS}(2,0,0,2)-\mathrm{DIR}(2,0)$

\begin{tabular}{|c|c|c|c|c|}
\hline & Modelo 1 & Modelo 2 & Modelo 3 & Modelo 4 \\
\hline c (regime 1$)$ & $\begin{array}{r}-0,598 \\
(0,493)\end{array}$ & $\begin{array}{r}-0,590 \\
(0,646)\end{array}$ & $\begin{array}{r}-0,704 \\
(0,555)\end{array}$ & $\begin{array}{r}-0,697 \\
(0,512)\end{array}$ \\
\hline$c$ (regime 2) & $\begin{array}{l}0,895^{*} \\
(0,128)\end{array}$ & $\begin{array}{l}0,888^{*} \\
(0,105)\end{array}$ & $\begin{array}{c}0,891 \\
(0,109)\end{array}$ & $\begin{array}{l}0,895^{*} \\
(0,130)\end{array}$ \\
\hline $\mathrm{y}(-1)$ & $\begin{array}{l}0,341^{*} \\
(0,074)\end{array}$ & $\begin{array}{l}0,358^{*} \\
(0,075)\end{array}$ & $\begin{array}{l}0,352^{*} \\
(0,075)\end{array}$ & $\begin{array}{l}0,338^{*} \\
(0,075)\end{array}$ \\
\hline$y(-2)$ & $\begin{array}{r}-0,055 \\
(0,059)\end{array}$ & $\begin{array}{r}-0,067 \\
(0,061)\end{array}$ & $\begin{array}{r}-0,066 \\
(0,063)\end{array}$ & $\begin{array}{r}-0,055 \\
(0,061)\end{array}$ \\
\hline $\mathrm{g}$ (regime 1$)$ & $\begin{array}{l}0,399 \\
(0,243)\end{array}$ & n.a. & n.a. & $\begin{array}{c}0,373 \\
(0,248)\end{array}$ \\
\hline $\mathrm{g}$ (regime 2 ) & $\begin{array}{c}0,029 \\
(0,054)\end{array}$ & n.a. & n.a. & $\begin{array}{c}0,030 \\
(0,054)\end{array}$ \\
\hline i (regime 1 ) & $\begin{array}{l}0,018 \\
(0,041)\end{array}$ & $\begin{array}{l}0,023 \\
(0,056)\end{array}$ & $\begin{array}{l}0,013 \\
(0,040)\end{array}$ & $\begin{array}{l}0,014 \\
(0,037)\end{array}$ \\
\hline i (regime 2) & $\begin{array}{l}0,038^{*} \\
(0,010)\end{array}$ & $\begin{array}{l}0,036^{*} \\
(0,011)\end{array}$ & $\begin{array}{l}0,037^{*} \\
(0,009)\end{array}$ & $\begin{array}{l}0,027^{*} \\
(0,013)\end{array}$ \\
\hline $\operatorname{ctl}(-2)($ regime 1$)$ & $\begin{array}{l}0,059 \\
(0,110)\end{array}$ & $\begin{array}{c}0,130 \\
(0,120)\end{array}$ & $\begin{array}{l}0,162 \\
(0,122)\end{array}$ & $\begin{array}{c}0,089 \\
(0,125)\end{array}$ \\
\hline $\operatorname{ctl}(-2)$ (regime 2$)$ & $\begin{array}{r}-0,060^{*} \\
(0,012)\end{array}$ & $\begin{array}{r}-0,059^{*} \\
(0,012)\end{array}$ & $\begin{array}{r}-0,059^{*} \\
(0,013)\end{array}$ & $\begin{array}{r}-0,061^{*} \\
(0,013)\end{array}$ \\
\hline $\operatorname{ctl}(-3)($ regime 1$)$ & n.a. & n.a. & $\begin{array}{l}0,085 \\
(0,120)\end{array}$ & $\begin{array}{l}0,051 \\
(0,106)\end{array}$ \\
\hline $\operatorname{ctl}(-3)$ (regime 2) & n.a. & n.a. & $\begin{array}{r}-0,002 \\
(0,013)\end{array}$ & $\begin{array}{r}-0,001 \\
(0,013)\end{array}$ \\
\hline sigma (regime 1 ) & $\begin{array}{l}1,352^{*} \\
(0,278)\end{array}$ & $\begin{array}{l}1,502^{*} \\
(0,308)\end{array}$ & $\begin{array}{l}1,475^{*} \\
(0,299)\end{array}$ & $\begin{array}{l}1,341^{*} \\
(0,278)\end{array}$ \\
\hline sigma (regime 2 ) & $\begin{array}{l}0,439^{*} \\
(0,074)\end{array}$ & $\begin{array}{l}0,461^{*} \\
(0,074)\end{array}$ & $\begin{array}{l}0,454^{*} \\
(0,068)\end{array}$ & $\begin{array}{l}0,436^{*} \\
(0,072)\end{array}$ \\
\hline$p_{-}(1 \mid 1)$ & $\begin{array}{l}0,557^{*} \\
(0,194)\end{array}$ & $\begin{array}{l}0,566^{*} \\
(0,205)\end{array}$ & $\begin{array}{l}0,599^{*} \\
(0,176)\end{array}$ & $\begin{array}{l}0,572^{*} \\
(0,191)\end{array}$ \\
\hline$p_{-}(1 \mid 2)$ & $\begin{array}{l}0,178 \\
(0,095)\end{array}$ & $\begin{array}{l}0,149^{*} \\
(0,076)\end{array}$ & $\begin{array}{l}0,146 \\
(0,078)\end{array}$ & $\begin{array}{l}0,175 \\
(0,095)\end{array}$ \\
\hline AIC & 2,825 & 2,808 & 2,864 & 2,884 \\
\hline Ver, & $-74,976$ & $-76,454$ & $-76,220$ & $-74,860$ \\
\hline Teste LR & $\begin{array}{l}34,943 \\
(0,0000)\end{array}$ & $\begin{array}{l}36,187 \\
(0,0000)\end{array}$ & $\begin{array}{l}36,620 \\
(0,0000)\end{array}$ & $\begin{array}{l}35,096 \\
(0,0000)\end{array}$ \\
\hline
\end{tabular}

\footnotetext{
${ }^{*}$ Significância estatística de $5 \%$.

${ }^{* *}$ Desvio padrão em parêntesis, exceto para o teste LR em que foi reportado o p-valor.

O Modelo 2 possui a melhor adequação estatística.
} 
Tabela A.4: Estimativas com multiplicadores fiscais dependentes do regime no modelo MS(1,0,0,2)-DIR(1,0)

\begin{tabular}{|c|c|c|c|c|}
\hline & Modelo 1 & Modelo 2 & Modelo 3 & Modelo 4 \\
\hline$c($ regime 1$)$ & $\begin{array}{l}0,731^{*} \\
(0,116)\end{array}$ & $\begin{array}{l}0,794^{*} \\
(0,097)\end{array}$ & $\begin{array}{l}0,813^{*} \\
(0,099)\end{array}$ & $\begin{array}{l}0,756^{*} \\
(0,115)\end{array}$ \\
\hline$y(-1)$ & $\begin{array}{l}0,359^{*} \\
(0,072)\end{array}$ & $\begin{array}{l}0,352^{*} \\
(0,070)\end{array}$ & $\begin{array}{l}0,345^{*} \\
(0,070)\end{array}$ & $\begin{array}{l}0,350^{*} \\
(0,070)\end{array}$ \\
\hline $\mathrm{g}$ (regime 1$)$ & $\begin{array}{l}0,241 \\
(0,319)\end{array}$ & n.a. & n.a. & $\begin{array}{l}0,305 \\
(0,327)\end{array}$ \\
\hline $\mathrm{g}$ (regime 2 ) & $\begin{array}{l}0,063 \\
(0,057)\end{array}$ & n.a. & n.a. & $\begin{array}{l}0,059 \\
(0,057)\end{array}$ \\
\hline i (regime 1) & $\begin{array}{r}-0,014 \\
(0,046)\end{array}$ & $\begin{array}{r}-0,017 \\
(0,047)\end{array}$ & $\begin{array}{r}-0,007 \\
(0,048)\end{array}$ & $\begin{array}{r}-0,002 \\
(0,047)\end{array}$ \\
\hline i (regime 2) & $\begin{array}{l}0,033^{*} \\
(0,010)\end{array}$ & $\begin{array}{l}0,034^{*} \\
(0,010)\end{array}$ & $\begin{array}{l}0,035^{*} \\
(0,010)\end{array}$ & $\begin{array}{l}0,033^{*} \\
(0,010)\end{array}$ \\
\hline $\operatorname{ctl}(-2)$ (regime 1$)$ & $\begin{array}{l}0,027 \\
(0,140)\end{array}$ & $\begin{array}{l}0,053 \\
(0,141)\end{array}$ & $\begin{array}{l}0,021 \\
(0,144)\end{array}$ & $\begin{array}{r}-0,012 \\
(0,145)\end{array}$ \\
\hline $\operatorname{ctl}(-2)$ (regime 2$)$ & $\begin{array}{r}-0,062^{*} \\
(0,013)\end{array}$ & $\begin{array}{r}-0,061^{*} \\
(0,012)\end{array}$ & $\begin{array}{r}-0,063^{*} \\
(0,013)\end{array}$ & $\begin{array}{r}-0,065^{*} \\
(0,013)\end{array}$ \\
\hline $\operatorname{ctl}(-3)($ regime 1$)$ & n.a. & n.a. & $\begin{array}{r}-0,080 \\
(0,129)\end{array}$ & $\begin{array}{r}-0,094 \\
(0,128)\end{array}$ \\
\hline $\operatorname{ctl}(-3)$ (regime 2$)$ & n.a. & n.a. & $\begin{array}{r}-0,006 \\
(0,014)\end{array}$ & $\begin{array}{r}-0,006 \\
(0,014)\end{array}$ \\
\hline sigma (regime 1 ) & $\begin{array}{l}1,951^{*} \\
(0,400)\end{array}$ & $\begin{array}{l}2,024^{*} \\
(0,423)\end{array}$ & $\begin{array}{l}1,991^{*} \\
(0,407)\end{array}$ & $\begin{array}{l}1,914^{*} \\
(0,385)\end{array}$ \\
\hline sigma (regime 2 ) & $\begin{array}{l}0,481^{*} \\
(0,065)\end{array}$ & $\begin{array}{l}0,482^{*} \\
(0,067)\end{array}$ & $\begin{array}{l}0,478^{*} \\
(0,065)\end{array}$ & $\begin{array}{l}0,478^{*} \\
(0,064)\end{array}$ \\
\hline$p_{-}(1 \mid 1)$ & $\begin{array}{l}0,619^{*} \\
(0,197)\end{array}$ & $\begin{array}{l}0,584^{*} \\
(0,209)\end{array}$ & $\begin{array}{l}0,588^{*} \\
(0,201)\end{array}$ & $\begin{array}{l}0,618^{*} \\
(0,190)\end{array}$ \\
\hline$p_{-}(1 \mid 2)$ & $\begin{array}{l}0,128 \\
(0,068)\end{array}$ & $\begin{array}{l}0,137 \\
(0,073)\end{array}$ & $\begin{array}{l}0,1137^{*} \\
(0,074)\end{array}$ & $\begin{array}{l}0,127 \\
(0,069)\end{array}$ \\
\hline AIC & 2,922 & 2,887 & 2,941 & 2,972 \\
\hline Ver, & $-80,039$ & $-80,956$ & $-80,636$ & $-79,617$ \\
\hline Teste LR & $\begin{array}{l}25,329 \\
(0,0001)\end{array}$ & $\begin{array}{l}28,369 \\
(0,0000)\end{array}$ & $\begin{array}{l}28,819 \\
(0,0000)\end{array}$ & $\begin{array}{l}25,980 \\
(0,0005)\end{array}$ \\
\hline
\end{tabular}

\footnotetext{
${ }^{*}$ Significância estatística de $5 \%$.

${ }^{* *}$ Desvio padrão em parêntesis, exceto para o teste LR em que foi reportado o p-valor.

O Modelo 2 possui a melhor adequação estatística.
} 